\title{
IMPROVING STUDENTS' VOCABULARY MASTERY BY USING WORD WALLS STRATEGY AND ALPHABOXES STRATEGY TO UNDERSTAND DESCRIPTIVE TEXT
}

\author{
Mansye Sekewael \\ Post-Graduate Students, English Study Program \\ Pattimura University - Ambon \\ E-mail: sekewaelmansye@yahoo.com \\ Wanti Josinta Maria Leni \\ English teacher of SMP Maria Mediatrix, Ambon, Indonesia \\ E-mail:wantijsl@gmail.com
}

APA Citation: Sekewael, M. \& Leni, W. J. M. (2015). Improving students' vocabulary mastery by using word walls strategy and alphaboxes strategy to understand descriptive text. Indonesian EFL Journal, 1(2), 242-249

Abstract: The purpose of this research was to measure how far the Words Walls Strategy and Alphaboxes Strategy can improve students' vocabulary mastery in understanding descriptive text. This was the kind of action research where the writer tried to collaborate his idea with the English teacher of the seventh grade of SMP Naskat Maria Mediatrix Ambon to gain the data of his research. the writer conducted his research at the first grade of SMP Naskat Maria Mediatrix in 2014/2015 Academic year. There are 22 students at that grade as the subjects of this research. In applying those strategies, There were two cycles: the first cycle consisted of six meetings where three meetings for use of Word Walls Strategy and Alphaboxes Strategy was sucessful in improving students' vocabulary mastery in implementing Words Walls Strategy and another three meetings for the Alphaboxes strategy. For the second cycle, the writer used four meetings for applying both strategies. The writer used the students' test result to measure the improvement of their vocabulary achievement. The writer found out that there were a significant differences scores after implementing both strategies. It proved that the students' understanding of descriptive text well toward those strategies.

Keywords: vocabulary mastery, word walls strategy, alphaboxes strategy, descriptive text.

\section{INTRODUCTION}

English has been considered as an essential language to be learnt in order to meet the communication needs in this globalization era. Taking into account the benefits of English, Indonesia has organized English to be taught in formal school as a compulsory subject. As stated in standard of content by Kemendikbud 2013, the teaching of foreign language, specifically English, is aimed to develop students' ability to communicate with world society. Therefore, it is taught in different kind of grade levels. The teaching includes the teaching of the four skills, listening, speaking, reading, and writing and each of the micro skills.

Vocabulary is one of crucial aspects to support those skills. As stated by Richards and Renandya (2002), vocabulary is a core component of language proficiency and provides much of the basis of how well learners speak, listen, and write. The vocabulary mastery will affect someone's ability in using the language either in spoken or written form. In listening skill, to be able to understand someone utterance, people should know what the meaning of words and sentences being said. Therefore, they know the intention of the utterance and are able to react either through action or answer it using spoken utterance, which here, they have to use words to do that. Additionally, to be able to understand what people is reading, they should be able to understand the meaning that is being conveyed through the written words. And as what needed in speaking, 
people should be able to arrange words to convey meaning in writing. Moreover, they should be able to spell the words and write them down. Although arranging words is not the only way in conveying meaning because there are also paralanguage and context which assist, but in languages, vocabulary will be the most crucial aspect.

As stated by Wilkins in Thornbury (2002), "Without grammar very little can be conveyed, without vocabulary nothing can be conveyed." It tells us that if someone wants to be able to convey meaning they need vocabulary. Although someone has known sentence structure but if he/she does not mastery vocabulary, he/she will remain unable to say or write anything and the grammar knowledge will be useless. Thus, by improving the vocabulary, it will be a basic for someone to communicate what is in their mind using the targeted language.

As a matter of fact, the researchers assumed that the students' learning vocabulary development, especially junior high school students, is somewhat causing apprehension. Based on the preliminary study that was conducted by researcher on grade VII of SMP Naskat Maria Mediatrix Ambon through observation and interview in the class during two weeks, the researcher wanted to know about the students understanding of vocabularies. First, in the pre-activity, the teacher just asked to write what the teacher wrote on the whiteboard, and then she explained about the lesson and gave several questions. Yet, only some students could answer the questions. While in the post activity, the teacher asked some students again regarding to the topic taught, they did not answer her questions. So, the writer interviewed the students and they did not understand about the text because it contained unfamiliar words that should be clearly explained to them. Consequently, they preferred to keep silent during the lesson.

Concerning to the problems above, it shows that the condition or the atmosphere during learning process always could not improve students' knowledge of vocabulary. In learning process, students need different and enjoyable atmosphere. According to Kline in Windura (2008), learning is more effective if it is done in a pleasant atmosphere. Gunning (2000) suggested that creating an interesting atmosphere of word learning can have a significant impact upon development of students. So the writer tried to overcome the problems above by applying two strategies namely "Word Wall and Alphaboxes strategies" to increase the students vocabulary in understanding the descriptive text. both of those strategies were separated explanations as follow:

The first strategy that the writer applied was "Word Walls Strategy". Erin (2011) states that interactive words walls showcase well-selected words; they help teachers build a foundation for student content vocabulary comprehension. They also support word-learning strategies by highlighting root words, suffixes, prefixes, and their meanings. This helps students decode meaning in text. additionally, when students use the word walls they become more conscious of words and definitions. This support content comprehension. It also help students become aware of vocabulary in the world around them.

The second one was called "Alphaboxes Strategy". Hoyth (1999) states that Alphaboxes is a strategy which encourages student to interact with text. In addition, Alphaboxes helps student activate prior knowledge, build vocabulary, and increase comprehension. Kimberly (2014) adds that Alphaboxes is an ideal strategy for students to work collaboratively with a partner or small group to engage with informational text. The Common Core State Standards encourage a shift toward using more informational text with students. Even first grade students can use alphaboxes in a small group as a follow-up activity with informational storybooks. Morrison \& Wlodarczyk (2009) conclude that the Alphaboxes strategy requires students to move from simple recall of factual information to going beyond the information presented in the text. Generating questions, making connections, providing explanations, identifying and discussing unfamiliar vocabulary words, and presenting alternative perspectives are all higher-level cognitive processes that increase learning (Block \& Johnson, 2002; Duke \& Pearson, 2002; Pressley, 2006). Additionally, when students 
work with one another, their thinking is distributed among group members, and participants share cognitive responsibility while externalizing their thoughts as they work through tasks (Palincsar \& Herrenkohl, 1999).

The description above related with those strategies which were applied by the teacher can guarantee that they would master vocabularies in understanding the descriptive texts for several reasons: (1) To brainstorm strategy to elicit students' prior knowledge and active their learning; (2) To find out the interesting words which are well known by the students; (3) To make the students more active in discussing their important words to the whole class so all students will get the same perception of the those words themselves; (4) To make reading comprehension looks still alive; (5) To motivate students in comprehending their vocabularies (Morrison \& Wlodarczyk, 2009).

Based on the background of the study, the research problem was formulated as the following: "is the students' vocabulary achievement significantly improved through Word Wall strategy and Alphaboxes strategy in understanding descriptive text?

\section{METHOD}

The research design was "Classroom Action Research (CAR)". In conducting CAR, the writer used Kemmis and MC Taggart's model (1982). Theoretically, this model includes a number of cycles as many as the writer needs. Each cycle has several phases. There were two cycles in doing this research.

In conducting the research, the writer applied Word Wall Strategy and Alphaboxes Strategy in in improving students' vocabulary through descriptive texts. the subjects of the research were the students of the VIIth grade of SMP Naskat Maria Mediatrix Ambon in Academic year 2014/2015. This class consisted of 22 students were eligible for data collection.

Before doing the real action, the teacher designed the lesson plan. The lesson plan was made in order to help the teacher to identify the students' need, preference, and also to motivate them to learn. The lesson plan was arranged and develop on the basis of the first semester program. It covered topic to be taught, the objectives, the steps of the teaching and learning process, and the media used.

The action was implemented in two cycles consisted of ten meetings. In the first cycle, three meetings are provided for applying word walls strategy and three meeting for Alphaboxes strategy. For the second cycle each of those strategies had applied twice. The purpose of applying those strategies for understanding descriptive texts.

For applying descriptive text, the teacher used Word wall strategy with the following procedures:

1) Preparation

The teacher trys to select a place in the room for his word wall. Large sheets of poster paper or a dedicated whiteboard work well.

2) Building your Word Wall Before the teacher begins reading a text (a descriptive text) or studying new material, assign students, possibly working in pairs, a term to define for the class word wall. The teacher can also requires students to present an image or graphic that represents the meaning of this word. Associating an image with a word is one way to help students remember definitions.

3) Adding to Your Word Wall New terms can be added to the word wall as needed. Students can also update the definitions on their word wall as they develop a deeper understanding of key terms.

While in applying Alphaboxes strategy, the procedures were as follow:

a) The teacher divided the class into small group of two. In pairs they discussed about one of topic related with descriptive text. it is "A Giraffe"

b) He distributed a blank of Alphabox sheet to each student.

c) He asked the students to think of words and phrases associated with a particular topic and record their ideas on their own Alphabox sheet. They should do this independently for a specified period of time.

* E.g., Consider the topic of Giraffe. Think about words and phrases 
you know associated with box. Giraffe. Think independently and record your ideas in the appropriate box. For example, one thing I think of regarding Giraffe is "neck things". I would record this phrase in the " $N$ "

4) Prompt students work with their partners or in small groups to compare their ideas. Individuals should add to, correct, or clarify their own written record.

5) The teacher facilitated a class discussion of the words and phrases associated with the topic.

* Consider using structures such as Interaction Sequence to facilitate the group discussion.

* Consider creating an Alphabox sheet. Have students add their ideas to one document.

6) All those words that they had could help them understand the content of the descriptive text before they did answering several questions related to the text.

To obtained complete and valid data, the writer used a number of instruments for recording, measuring or controlling data. The instruments which were used included an observation sheet, tests, questionnaire, documentation, and an interview guide. Observation was conducted to examine the process that happened during the action and the note the classroom events. It was intended to know whether the action was in line with the planning used in the teaching and learning process. The writer implemented non-participant observation. He observed the subject of the study without taking an active part in the situation. The observation sheet used was a checklist. The checklist was used to check if the implementation of Word Wall Strategy and Alphaboxes Strategy were effective in class. Test were used to measure both strategies in improving students' vocabulary in understanding descriptive texts. There were three tests which were done during the research. They were orientation test, Post test in Cycle I, and Post Test in Cycle II. The result of the tests were compared with the criteria of success to know whether the students' skill in vocabulary improved. To gain the data, the writer used the questionnaire items addressed to the students and the teacher as the subject of the research. Questionnaire was used to know the English teacher's opinion and students' responses related to the use of Word Wall Strategy and Alphaboxes Strategy". the writer also used documentation such as syllabus and descriptive texts. Finally, the goal of interviews to explore the students' opinion deeply in improving their vocabulary in understanding descriptive texts by using Word Wall Strategy and Alphaboxes Strategy.

\section{RESULTS AND DISCUSSION}

Before doing his research, the writer gave a general test which is called Pre-test. the test consist of some homonyms and antonyms. The writer wanted to measure how far the students in the seventh grade of SMP Maria Mediatrix Ambon understanding the words through a text. He provided local content materials in descriptive text. There are 3 (three) short texts which were consisted of 20 questions. Those questions were in multiple choices. The result of the pre-test was provided in the figure 1 below: 


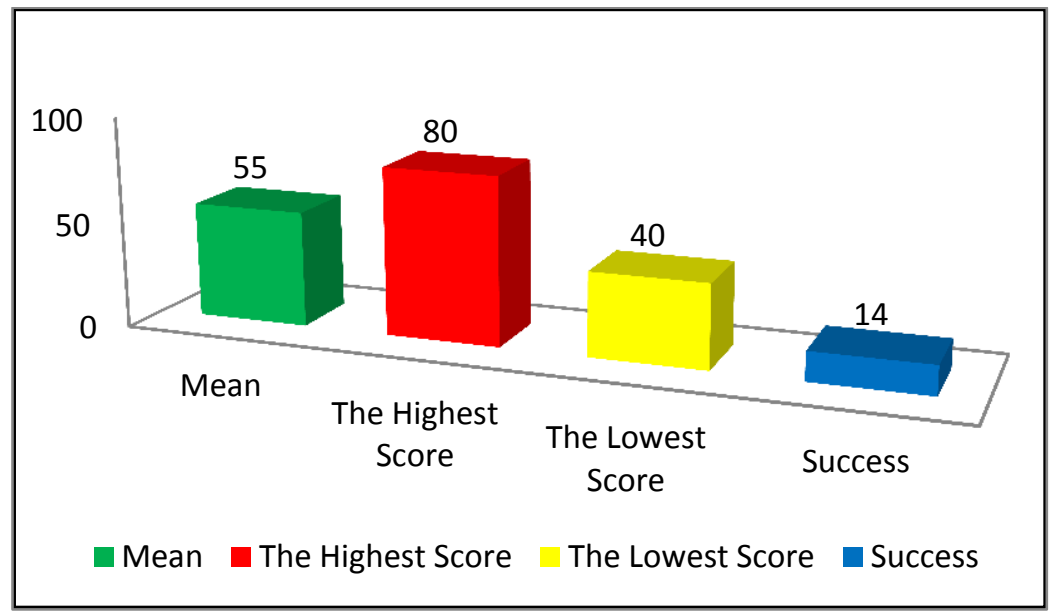

Figure 1. The result of pre-test.

The result showed that the students were under the average level. Three students were passed the test based on the standard of the research. Thus, the total numbers of students succeeded were $14 \%$. The highest score could reach 80 and the lowest one was 40 while the mean of the pre-test was 55 . It could state that this class needed to get a strategy in comprehending their vocabulary.

Gaining the result as shown in figure 4.1, made the writer did a short interview with the English teacher and five of the seventh grade students of SMP Naskat Maria Mediatrix. The interview was done to know what the best strategy to be applied to make them more understand about the text through vocabulary. In the interview, the students were asked whether the descriptive text was difficult for them if they have lack of vocabulary. Some of the students answered "yes" because they thought that it was hard to capture all information of the content in the descriptive texts because most of them have difficult words and they were new to them remembering that they were still in the seventh grade and some of them didn't get English since they were in elementary school. they also explained that they were not familiar with difficult words, idioms, and phrases. They gave their opinion about their reading habit, they said that they were not interest in reading because more information for them were still new and they felt bored doing reading tasks.
Seeing that fact, the writer provided some strategies for the English teacher to be discussed. She then agreed to choose two of them namely "Word Wall strategy and Alphaboxes Strategy". After getting the two strategies to be applied, the writer together with the English teacher tried to design lesson plans, English materials and evaluation tools in our planning. We planned to do two cycles in our research. But we didn't limit our research to the next cycle if we've failed in the last cycle ( $2^{\text {nd }}$ Cycle). We would teach the students using both Word Wall strategy and Alphaboxes Strategy. Each cycle in our research consisted of three meetings and the last meeting will be the test to measure the students comprehending about vocabulary through descriptive text.

We started our research in cycle one on February $2^{\text {nd }}, 2015$. Two meetings had done successfully (9 $9^{\text {th }}$ and $16^{\text {th }}$ of February 2015) for Word wall strategy, and then we did posttest of the $1^{\text {st }}$ cycle for the students on February $23^{\text {rd }}, 2015$. We still used the same materials but different in the content of the text to be applied using Alphaboxes Strategy. We started our research on February 23rd and continue the next two meeting on $2^{\text {nd }}$ and $9^{\text {th }}$ March, 2015. After doing the evaluation of the $1^{\text {st }}$ cycle of Alphaboxes Strategy, we then compare them through the result as shown in the following figure 2 : 


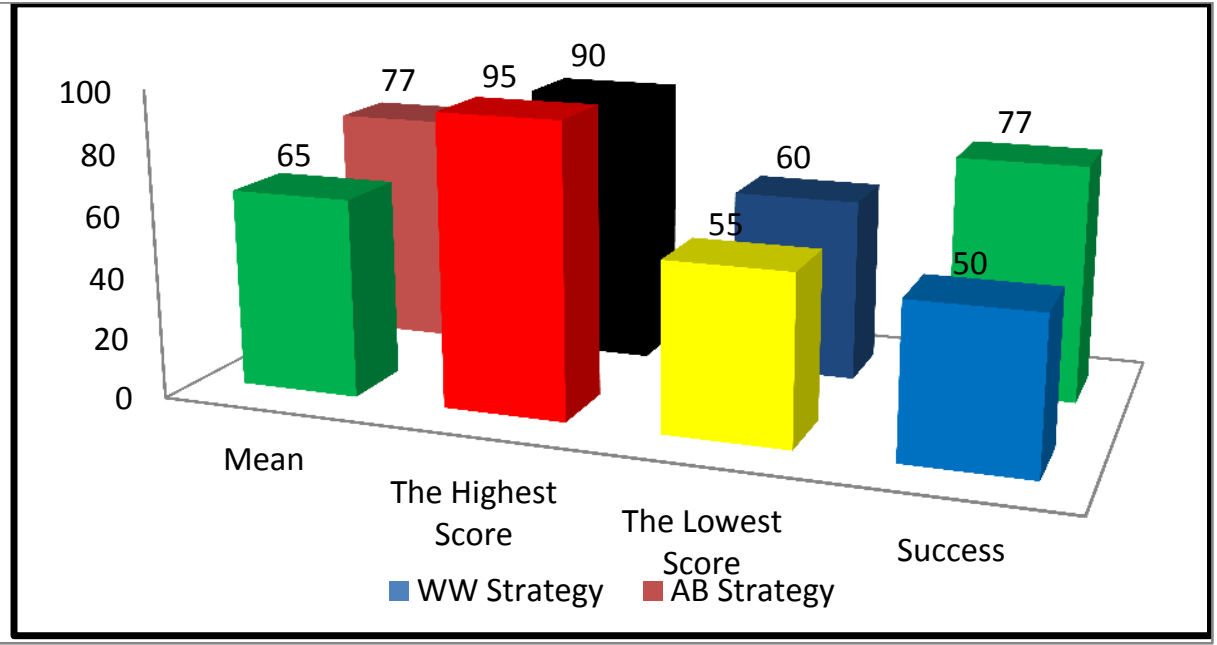

Figure 2. The result of $1^{\text {st }}$ cycle

From the data above, we can stated that we need to do the next cycle because both Word Wall strategy and Alphaboxes Strategy couldn't reach the minimum standard of our research where we need the mean of the class was 75 and the total percentage of students' success was $80 \%$. As the realty shown in the data above was the mean in Word Wall Strategy was 65, the highest score was 95 and the lowest one was 55 . The percentage of students' success was $50 \%$. We need to do the next cycle to make our research would be success. The same problem we've got from Alphaboxes Strategy. Although the mean score was 77 and it stated that the students has been succeed but the total percentage in their success was $77 \%$ also and it could not answer the need of our research. We needed $80 \%$ for getting success in our research. That's why, both of us decided to continue our research in the next cycle (2 $2^{\text {nd }}$ Cycle).

Before starting our next research, we discussed about the strengthen and the weakness of Alphaboxes Strategy and Word Wall Strategy. During the first cycle we found (1) both strategies were new to the students so, they were confused for the first time during the implementation. For the next meeting, they were serious in doing those strategies; (2) the vocabularies in the texts could be understood fast because they have background knowledge with them. So when they did the tasks, some of them did not need to look for the meaning in the dictionaries. As those strategies helped them much; (3) the students were happy doing their tasks. As they did competition one another to prove that they could handle their problems. Sometimes they got difficult and need the teacher to explain a little to lead them understanding the concept of the materials.

The $2^{\text {nd }}$ cycle has done on March $16^{\text {th }}$, 23rd and 30th, 2015 for Word Wall Strategy and April 6 ${ }^{\text {th }}, 13^{\text {th }}$, and $20^{\text {th }} 2015$ for Alphaboxes Strategy. The result can be shown in the figure 3 below: 


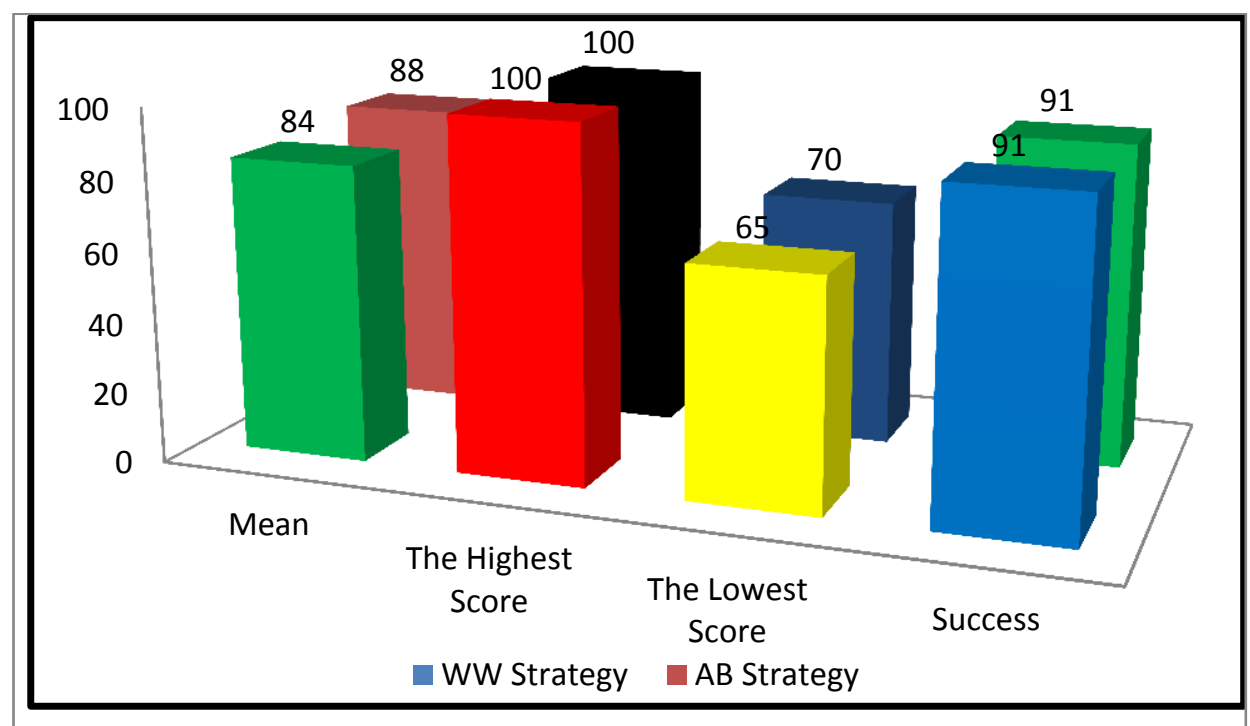

Figure 3. The result of $2^{\text {nd }}$ cycle

The figure 3 showed that there was a significant different in the result of the test in $2^{\text {nd }}$ cycle. The mean score of Word Wall Strategy was 84 and Alphaboxes strategy was 88. The highest score of both strategies were the same (100). For the lowest score, the alphaboxes strategy was 70 while the word wall strategy was 65 but both Word Wall strategy and Alphaboxes Strategy had the same percentage of success. Only two of the students were fail. So, the total number of the students' success was $91 \%$.

From the result of the test above, the writer concluded that the research that has done will be stopped because the criteria of success had already reached. Thus, we couldn't continue our research to the $3^{\text {rd }}$ cycle.

It suggested that the use of Word Wall Strategy and Alphaboxes Strategy" can improve students' vocabulary mastery in understanding the descriptive text of the second semester students in VIIth grade of SMP Naskat Maria Mediatrix Ambon. It was obviously seen that the score of the students in vocabulary kept increasing from the orientation test until the post-test of cycle 2 . It was proved by the data which show that the mean of the students in the post-test II for "Word Wall Strategy" was 84 and for "Alphaboxes Strategy" was 88 if we compared in the pre-test where the result of the students in "Word Wall Strategy" was 65 and "Alphaboxes Strategy" was 77.
The qualitative data taken from observation sheet and questionnaire sheet also showed that the students' questionnaire toward the implementation of Word Wall Strategy and Alphaboxes Strategy" can be described as follow: 77,27\% were interested in learning English text by knowing the meaning of vocabulary first and $22,28 \%$ were still not interest at all. 81,82\% showed their interesting after applying "Word Wall Strategy and Alphaboxes Strategy", 13,64\% were still confused and 4,54 was not give his answer. In understanding a descriptive texts, $95,45 \%$ stated that they were easy to understand them and enjoy reading them after the implementation of both strategies mention previously. While $4,54 \%$ did not give his respond.

From the rest of the data above, both Word Wall Strategy and Alphaboxes Strategy" were very helpful in improving students' vocabulary mastery in understanding the descriptive texts. it was noted during teaching and learning process, they enjoyed their class very much.

\section{CONCLUSION}

Based on the research finding, the conclusion can be drawn as follow: (1), the use of Word Wall Strategy and Alphaboxes Strategy" had positive impact on the improvement students' vocabulary mastery and also produced their interest in reading descriptive text; (2) from the observation and documentation, the writer knew that the 
English teacher and the students did all of the stages in the teaching and learning process starting from preparing lesson plans to do pre-activities, whilst-activities and post activities well; (3) from the interview with the English teacher and the students, the writer got positive responds from them concerning to the applying those strategies. According to them, those strategies were attractive and helpful to practice their vocabularies; (4) the result of the questionnaire showed that In understanding a descriptive texts, $95,45 \%$ stated that they were easy to understand them and enjoy reading them after the implementation of both strategies mention previously. While $4,54 \%$ did not give his respond.

Based on the above conclusions, it is recommended that teachers who teach vocabularies in reading texts should apply Word Wall Strategy and Alphaboxes Strategy. those strategies can help students easily to understand the content of the texts. For the students, they can use and have more exercises with those strategies in daily activities in order to improve their capability in understanding all genre of texts.

\section{REFERENCES}

Erinn L. Henrichs, B. S. (2011). Interactive Word Walls and Student Perceptions of Vocabulary.Thesis. San Marcos: Texas State University

Duke, N. K., \& Pearson, P. D. (2002). Effective reading practices for developing comprehension. In A.E. Farstrup \& S.J. Samuels (Eds.), What research has to say about reading instruction, 3rd edition., Newark, DE: International Reading Association

Gunning, T. G. (2000). Creating literacy instruction for all children. Boston: Allyn and Bacon

Hoyt, L. (1999). Revisit, reflect, retell. Portsmouth, NH: Heinemann

Kemmis, S. and McTaggart, R., eds. (1982) The action research planner, third edition. Victoria: Deakin University.

Kimberly, T. (2014). Alphaboxes: 14 Strategies to Use Before, During, \& After Reading $\{12$ Days of Literacy\}. Retrivted from:

http://www.learningunlimitedllc.com/2014/01/12days-literacy-alphaboxes-10-simplestrategies/

Morrison, V., \& Wlodarczyk, L. (2009, October). Revisiting Read-Aloud: Instructional Strategies That Encourage Students' Engagement With Texts. The Reading Teacher 63(2), 110-118.

Palincsar, A. S., \& Herrenkohl, L. (1999). Designing collaborative contexts: Lessons from three research programs. In A. M. O'Donnell \& A. King (Eds.), Cognitive perspectives on peer learning (pp. 151-177). Mahwah, NJ: Erlbaum.

Pressley, M. (2006). What the future of reading research could be. Paper presented at the International Reading Association's Reading Research 2006 Conference, Chicago, Illinois, April 2006.

Windura, S. (2008). Mind Map Langkah demi langkah. Jakarta: PT Elex Media Kompotindo. 